\title{
Communication Of Cancer Cells And Lymphatic Vessels In Cancer: Focus On Bladder Cancer
}

This article was published in the following Dove Press journal:

OncoTargets and Therapy

\author{
Zhang-song $\mathrm{Wu}^{\mathrm{I}-3, *}$ \\ Wa Ding ${ }^{1,3, *}$ \\ Jiajia Cai ${ }^{3,4}$ \\ Ghassan Bashir ${ }^{3}$ \\ Yu-qing $\mathrm{Li}^{2,3}$ \\ Song $\mathrm{Wu}^{\mathrm{I}-4}$
}

'Medical College, Shenzhen University, Shenzhen 518000, People's Republic of China; ${ }^{2}$ Department of Urological

Surgery, The Third Affiliated Hospital of Shenzhen University, Shenzhen

University, Shenzhen 5I8000, People's Republic of China; ${ }^{3}$ Shenzhen following Precision Medical Institute, The Third Affiliated Hospital of Shenzhen University, Shenzhen University, Shenzhen 518000, People's Republic of China; ${ }^{4}$ Medical College, Anhui University of Science and Technology, Huainan 23200I, People's Republic of China

*These authors contributed equally to this work
Correspondence: Song Wu

Department of Urological Surgery, The

Third Affiliated Hospital of Shenzhen

University, Shenzhen University, Shenzhen

518000 , People's Republic of China

Tel +86-18098928732

Email doctor_wusong@|26.com

\begin{abstract}
Bladder cancer is one of the most commonly diagnosed cancers worldwide and causes the highest lifetime treatment costs per patient. Bladder cancer is most likely to metastasize through lymphatic ducts, and once the lymph nodes are involved, the prognosis is poorly and finitely improved by current modalities. The underlying metastatic mechanism for bladder cancer is thus becoming a research focus to date. To identify relevant published data, an online search of the PubMed/Medline archives was performed to locate original articles and review articles regarding lymphangiogenesis and lymphatic metastasis in urinary bladder cancer (UBC), and was limited to articles in English published between 1998 and 2018. A further search of the clinical trials.gov search engine was conducted to identify both trials with results available and those with results not yet available. Herein, we summarized the unique mechanisms and biomarkers involved in the malignant progression of bladder cancer as well as their emerging roles in therapeutics, and that current data suggests that lymphangiogenesis and lymph node invasion are important prognostic factors for UBC. The growing knowledge about their roles in bladder cancers provides the basis for novel therapeutic strategies. In addition, more basic and clinical research needs to be conducted in order to identify further accurate predictive molecules and relevant mechanisms.
\end{abstract}

Keywords: bladder cancer, lymphangiogenesis, lymphatic metastasis, biomarkers, tumor progression, treatment

\section{Introduction}

UBC is the second most frequent malignant tumor of the urinary system, with the estimated 76,900 new cases, approximately 15,900 death in America during the year of 2016. ${ }^{1,2}$ Smoking is just an established risk factor for UBC. ${ }^{3}$ For histopathology, transitional cell carcinomas take account for nearly 90 percent of bladder cancers, the rest of UBC contains adenocarcinomas, squamous cell carcinomas, and undifferentiated bladder carcinomas. ${ }^{4}$ UBC frequently show the peculiarity of progression, referring to two closely related processes of invasion and metastasis, and which could serve as the remarkable common cause involved with cancerrelated deaths. ${ }^{5}$ Concerning the natural process, bladder cancer is generally divided into two distinct groups, such as non-muscle invasive bladder cancer (NMIBC), also referred to as superficial, and muscle-invasive bladder cancer (MIBC). Among the superficial tumors, which often recurs and invades the muscle after the transurethral initial resection, up to $50-70 \%$ recurrence $^{6}$ and $10-20 \%$ progressing to MIBC, ${ }^{7}$ respectively. MIBC may display as the high risk of metastatic malignant tumors and subsequently cause death, with the 5-year survival rate remarkably declining from $90 \%$ in $\mathrm{NMIBC}^{8}$ to $60 \%$ in comparison with MIBC. ${ }^{9}$ Even worse, 
approximately a quarter of patients suffering MIBC undergo radical cystectomy(refers to the removal of the bladder together with the prostate and seminal vesicles in this context), whereafter, unfortunately, show lymph node metastases later and die during the first five years after primary confirmed diagnosis. ${ }^{10,11}$

Tumor metastasis, including blood and lymphatic metastasis, is topmost of the dismal aspects of tumor progression. Besides, it is largely supposed that bladder cancer is most likely to disseminate from in-suit to distant organs through lymph ducts. Indeed, the detection of metastases within the sentinel lymph nodes is an essential prognostic factor for patient survival and select whether adjuvant therapies or not. ${ }^{12}$ Once the lymph nodes are in invasion $(\mathrm{Ln}+)$ in the $\mathrm{UBC}$, the poor prognosis will be defined in the future follow-ups, ${ }^{13}$ contributing to about 90 percent of cancer-specific death. ${ }^{14} \mathrm{Ln}+$ involves the new formation of lymphatic ducts in intratumoral and peritumoral regions at first, and next delivering of cancer cells to lymphatic vasculatures and spreading them to lymph nodes (LNs), finally inducing the settlement and proliferation of in LNs. ${ }^{15,16}$

It is anticipated that lymphangiogenesis plays vital roles in physiological (e.g., menstrual and hair cycle, ovarian follicle maturation, corpus luteum formation, and uterine implantation) and pathological (i.g., inflammation, wound healing and cancer.) processes. To date, the roles of lymphangiogenesis become a research hotspot in the aspect of unveiling mechanism of metastasis and exploring novel therapeutic strategies for individuals with urothelial carcinoma. It has been verified that lymphangiogenesis is an indispensable element for lymph nodes metastasis. Despite the increasing improvement in surgical techniques and adjuvant chemotherapy and immunotherapy, there are still poor treatment response and prognosis. ${ }^{17}$ In recent, the treatment options for advanced UBC mainly depends on conventional clinicopathological characteristics, such as tumor grade and stage information, though providing important prognostic information in UBC, they are of limited use in the prediction of cancer recurrence, progression, treatment response, and survival, ${ }^{18}$ partially due to the shortcomings of staging and grading subjectivity that can lead to highly observational error. ${ }^{19}$ Fortunately, Ln+ is an earlier event when occurs the progression of MIBC with significantly predictive values, and the lymphatic vessels in or in proximity to tumors could serve as the primary conduits for the spread of cancer cells. ${ }^{20}$ Moreover, thus, to unravel the lymphangiogenesis and lymph node invasion in UBC cries out for the treatment and surveillance in the future.

To date, the majority of research on lymphatics at the primary tumor has focused on the capacity of lymphatic vessels to facilitate the entry and transport of tumor cells; the influence of lymphatic location (intratumoral versus peritumoral); and the enlargement or collapse of the lymphatics during metastasis, ${ }^{21,22}$ and the potential predictable roles for tumor grade and stage. This review highlights the current knowledge about the anatomical structure of the lymphatic system and underlying cellular mechanisms of lymphangiogenesis, discusses the fatal molecules and defining signals that control these processes, as the promising pools of anti-lymphangiogenic targets. The implications of these findings for the advancement of novel diagnostics and therapeutics, and future cancer research, are also discussed.

\section{Lymphatic System And Its Role In Urothelial Carcinoma}

Despite the lymphatic system initially described in the 17 centuries, it is generally regarded as the "forgotten" the second angiology. ${ }^{23}$ In general, lymphatic conduits can fall into three separate types: initial blind-ended lymphatics, pre-collecting and collecting vessels. ${ }^{23,24}$ Next, we discuss several well-characterized mediators involved the lymphatics development, and their interaction between lymphatics and tumor progression, especially for bladder cancer.

There are several well-known regulators that can modulate mammalian lymphatic system development, such as Prospero homeobox transcription factor-1 (PROX-1), ${ }^{25}$ SRY-related HMG-box(SOX)-18, ${ }^{26}$ and the vascular endothelial growth factor-C (VEGF-C)/VEGF receptor-3 (VEGFR-3) axis, ${ }^{27}$ reader could extensively and comprehensively overview the mediator of the formation of the lymphatic system in several published reviews. ${ }^{28-30}$ Enabling signal for lymphatic endothelial cells (LECs) differentiation is deemed to be regulated by mitogen-activated protein kinase/extracellular signalregulated kinase (MAPK/ERK) signaling, and subsequently initiate SOX-18 to facilitate the upregulation of PROX-1, ${ }^{31,32}$ which immediately leads to the PROX-1 expression to trigger the differentiation of LECs in turns, as characterized by the well-characterized lymphangiogenic genes expression including VEGFR-3, podoplanin, integrin a9, and chemokine (C-C motif) ligand 21(CCL21), ${ }^{33,34}$ and also directs endothelial cells toward a lymphatic fate in vivo. ${ }^{35}$ Further, the maintenance of LEC identity is reversible and dependent on PROX-1 
expression, ${ }^{36}$ which regulates VEGFR3 expression. ${ }^{37}$ During the processes, the transcription factor musculoaponeurotic fibrosarcoma oncogene homolog B(MAFB) shows a potency in the maintenance of the LEC phenotype by overexpressing SOX-18 and PROX-1, while conversely, DLL4/Notch signaling downregulates the COUP transcription factor-2 (COUPTF-2)(also known as nuclear receptor subfamily 2 group F member 2; NR2F-2) and PROX-1 expression, maintaining venous endothelium cells characteristics. VEGF-C is an established lymphatic-associated growth factor. ${ }^{38}$ VEGF-C crosstalks with its initial receptor, VEGFR-3, which activates the MAPK/ERK and phosphatidylinositol 3-kinase (PI3K)/ protein kinase $\mathrm{B}(\mathrm{PKB} / \mathrm{AKT})$ signaling pathways, triggering LECs survival, migration, and proliferation. ${ }^{39}$ Contrarily, MAPK signaling is thought to be negatively mediated by the transcription factors fork head box protein $\mathrm{C} 1$ and $\mathrm{C} 2$ (FOXC1/FOXC2). ${ }^{40}$

It is starting as small initial blind-ended lymphatics that favor the absorption of interstitial fluid and cell in tissues. ${ }^{41,42}$ The initial lymphatic capillaries, surrounded by intermittent basement membrane with no vascular smooth muscle cells or pericytes, are non-contracting vessels characterized by a single layer of LECs and abluminal membrane of LECs connected to surrounding interstitial elastic fibers by the short anchoring filaments, ${ }^{42-44}$ and then flow into pre-collecting vessels and collecting vessels, further downstream, the collecting lymphatic vessels drain to the thoracic duct or the right lymphatic trunk, hereafter enter into the circulation systems ${ }^{23,24,45,46}$ (Figure 1). In general, the lymphatic vasculature, functioning unidirectionally, is a drainage network that starts in the interstitial tissue and ends mainly in draining into the venous circulation, which serves as three of cardinal functions, such as maintaining interstitial fluid homeostasis, ${ }^{47}$ immune surveillance and absorption of fat in the gastrointestinal tract. ${ }^{23}$ The lymphatic system involves the local progression and invasion in urothelial carcinoma, Recent reports pay attention to the role of lymphangiogenesis and lymphatic vessel density (LVD) and indicate that both them could serve as a potential prognostic marker and as a mechanism of metastatic dissemination in those patients with $\mathrm{UCB}^{48,49}$ Intratumoral

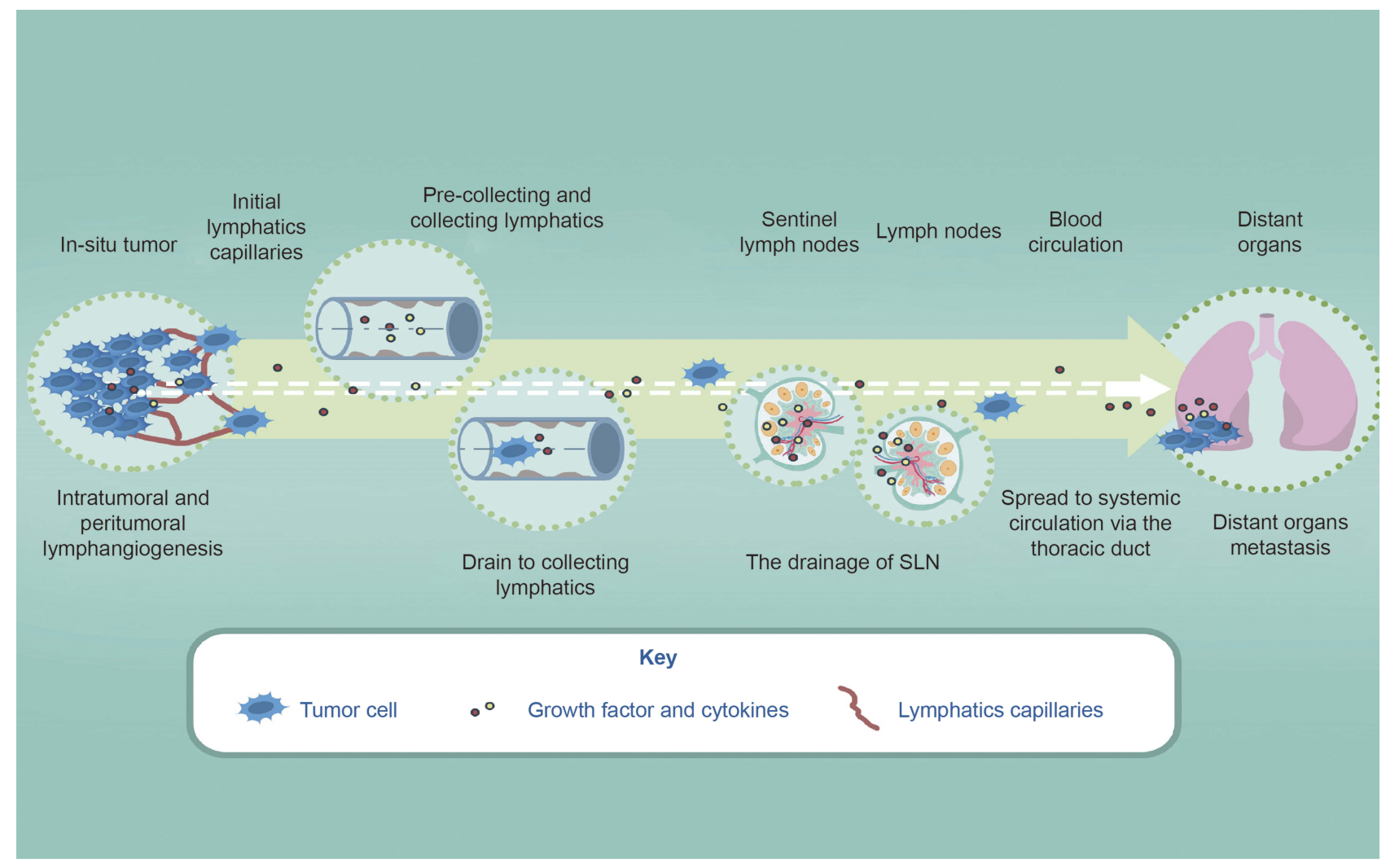

Figure I A simplified schematic of lymphatic metastasis in bladder cancer. Tumor cells in the tumor microenvironment produce factors (growth factors or cytokines) that induce sprouting growth of local initial lymphatic vessels. These factors, together with metastatic cells and immune cells, are transported via pre-collecting and collecting lymphatics to tumor-draining LNs. Tumor cells and other factors may then access systemic circulation through the thoracic duct, leading to spread to distant organs. Lymphangiogenesis in distant organs occurs as part of premetastatic niche formation and continues after the arrival of metastatic cells, potentially promoting further metastasis. Notes: Reprinted with permission from Elsevier from: Farnsworth R, Achen MG, Stacker SS. The evolving role of lymphatics in cancer metastasis. Curr Opin Immunol. 2018;53:64-73. ${ }^{46}$ Copyright (c) 2018 Elsevier Ltd. All rights reserved. 
lymphatics (ITLs) were quite small, irregular or flattened, and occasionally filled within tumor cells in the lumen, while peritumoral lymphatics(PTLs) were relatively disorganized and enlarged, and strictly located at the tumor periphery. ${ }^{50}$ Morphological investigations have suggested that ITLs are newly proliferating, while PTLs are likely to become preexisting lymphatic vessels. One study involved human breast cancer, indicated that LN metastasis could sufficiently proceed through the pre-existing lymphatic vessels, implying that lymphangiogenesis may not necessarily be involved at the tumor periphery regardless of ITL vessel density, ${ }^{51}$ another investigation also indicated that ITLs is unnecessary for metastasis to LNs in urothelial carcinoma and prostate cancer. ${ }^{52}$ Additionally, functional studies using assays for micro-lymphangiography and interstitial fluid pressure have indicated that ITLs may be nonfunctional. Meanwhile, multiple investigations in experimental models and human specimens have indicated that PTLs are more critical than ITLs for cancer metastasis cells. ${ }^{53}$ However, a majority of studies also have reported an association between ITLs and PTLs and aggressive features of invasive UCB and upper tract urothelial carcinoma. ${ }^{54,55}$ To conclude, it is unclear whether ITLs lack functions to date, ITLs can be detected in urothelial carcinomas conversely, despite the controversial role of ITLs lymphangiogenesis by neoplastic cells in regulating LNs metastasis yet, intratumoral lymphatics are high likelihood to sever as a risk factor for LNs metastasis and prognosis for patients with bladder cancer, thus targeting the intratumoral lymphatics is also imperative to diminish the spread of primary tumors as well as PTLs. More investigations need to explore and determine the precise underlying mechanism of how PTLs and ITLs to facilitate lymphatic metastasis in order to provide novel therapeutic strategies for individuals with urothelial carcinoma.

\section{The Gene Expressing Profiling}

It is generally understood the gene variation plays a vitally significant role in the emergence and development of carcinoma, associated with prognosis and cancer-specific survival as well. There are hundreds of thousands of gene mutation message to be distinguished on the basis of the fast development of sequencing technologies, however, the actual value of the gene expression signatures correlated with lymphangiogenesis and lymphatic metastasis in bladder cancer has not yet been elucidated, and we also do not make sure whether some of these gene alterations involved whether driver or passenger mutations. Nowadays, gene expression profiling for cancer has gained increasing attention owing to its ability to figure out a detailed and complete map to discover the molecular cancer subtypes at the transcriptome level, or based on the genetic and epigenetic alteration.

Several RNA-based expression data analysis assays indicate that gene differential expression in MIBC is associated with lymph node involvement, and to develop a list of gene expression models (GEM) predicts the pathological lymph node status in order to selecting patients for advanced neoadjuvant chemotherapy, ${ }^{56-58}$ a research, however, indicated that predictive efficacy could not be validated merely based on a qRT-PCR platform. ${ }^{59}$ Therefore, a novel gene screening method is advisable, which proposed 18-gene signatures highly predictive of lymphatic metastasis. ${ }^{60}$ In recent, a study demonstrates a nomogram for preoperatively predicting $\mathrm{LN}$ metastasis in bladder cancer, which shows favorable discriminatory ability and may offer help for clinical decision-making. ${ }^{61}$ A group fixes their concentration on the relationship between copy number variation and lymph node metastasis, consequently detect copy number gain at chr3p25 and chr11p11, approximately a set of 22 genes, which related to $\mathrm{Ln}+$ and survival in bladder cancer. ${ }^{62}$

\section{The Specific Biomarkers And Growth Factors For Lymphatic Systems}

The exact molecular mechanism of lymphangiogenesis and lymph node metastasis was poorly influenced by the shortage of promising biomarkers that reasonably differ lymphatic vessels from blood vasculatures in the intratumoral and intertumoral areas. Luckily, recent studies focus their attention on lymphangiogenesis as well as the interests in LEC markers in UBC, various lymphatic-associated proteins have been detected such as PROX-1, VEGFR-3, SOX-18, NR2F2, neuropilin 2 (NRP-2), FOXC2, and others, some of which have important functions in the development of the lymphatic vasculature. ${ }^{63,64}$ Nevertheless, only two of biomarkers have been widely implicated in neoplasm to identify newlyborn lymphatics: lymphatic vessel endothelial hyaluronic acid receptor 1 (LYVE1) and podoplanin. ${ }^{65}$ Multiple investigations give attention to the ITLs and PTLs, and their role in malignancy development and progression. Interestingly, Lymphovascular invasion (LVI) ${ }^{66-69}$ and high LVDs $^{70-72}$ could be strongly prognostic factor for tumor aggressiveness and an indicator of occult metastases in several malignancies, including UCB as well, ${ }^{13,73,74}$ while some retrospective analysis however controversially indicated LVDs is not associated with survival in various cancer in statistics (e.g., 
melanoma, breast cancer), thus, more research is needed in this part.

VEGF-C, VEGF-D, and their specific receptor, VEGFR-3 mark a profound milestone in the lymphatic commitment and metastasis, which are identified as guaranteeing prognostic indicators for malignant bladder cancer dissemination. ${ }^{75}$ Additionally, several findings suggest that VEGF-C and VEGF-D are not just stimulate lymphangiogenesis but also may influence angiogenesis. ${ }^{76}$ Indeed, some investigators reported that the roles of VEGF-C and VEGF-D associated with MVD to induce angiogenesis in cancer tissues. ${ }^{77}$ However, other investigators have supported the hypothesis that VEGFC and VEGF-D do not have an angiogenic function. ${ }^{78}$ Although numerous investigators speculated that the properties of VEGF-C and VEGF-D in lymphangiogenesis or angiogenesis might depend on the degree of their proteolytic processing, ${ }^{76}$ clear explanations for such different functions of VEGF$\mathrm{C}$ and VEGF-D were not provided by data from the present study. Current experimental and clinical studies mainly focus their attention on the roles of tumor-derived VEGF-C, VEGF-D, and their receptors for lymphangiogenesis and lymphatic metastasis, whereas tumor-associated stromal cells, especially stromal macrophages also could release VEGF-C and VEGF-D. ${ }^{79}$ Therefore, further investigations need to clarify and understand VEGF-C/ VEGF-D-VEGFR-3 axis as their potential in predictive biomarkers and novel therapeutic targets in patients with lymphatic metastasis. Neuropilin-2 was another factor with specific expression in lymphatic ducts, ${ }^{80}$ which could regulate the VEGF signaling pathway due to the peculiarity of coreceptor. ${ }^{81}$ The LYVE1, which positively applied to distinctively identify LVD, and thus promote the investigation of tumor-associated lymphangiogenesis in bladder cancer. ${ }^{82}$

Moreover, the transcription factor PROX-1 explicitly expressed in lymphatic vessel tissues but not blood vascular endothelium cell. ${ }^{83,84}$ Furthermore, it has been reported that PROX-1 could upregulate the LEC-specific markers, whilst represses that of blood vascular endothelial cells (BECs) markers. ${ }^{33,85}$ These in vitro and in vivo findings indicate that PROX-1 medicates the differentiation of LECs from embryonic BECs via functioning as a binary transcriptional switch, turning the BEC program off and the LEC program on. Since PROX-1 is recognized as a vital molecule to activate lymphatic development, molecular mechanisms how PROX-1 is induced during lymphatic development have been extensively investigated.
For example, SOX-18, a member of the SOX family of transcription factors, directly binds to PROX-1 promoter and subsequently initiates its expression during the differentiation program of venous BECs to LECs. ${ }^{26,86}$ Furthermore, PROX-1 requires the assistance of Ets family members for efficiently overexpressing the LEC-specific markers. To more specifically, several findings suggest that Ets-2 could stimulate expression of VEGFR-3, with the activation of its ligands-VEGF-C consistently, which suggests that cooperatively enhances PROX-1-induced lymphangiogenesis. ${ }^{87}$

Interestingly, the expression levels of VEGF-D, cyclooxygenase (COX)-2, and matrix metalloproteinase(MMP)-2 played vigorous influences in several processes, including malignant proliferation and lymphangiogenesis. ${ }^{88}$ Also, podoplanin accurately express in lymphatic vessels, the upregulation of this kind of transmembrane glycoprotein could promote various human cancer to disseminate to distant organ based on epithelial-mesenchymal transition(EMT). ${ }^{89}$ A commercially available antibody, named D2-40, correctly anchors human podoplanin $^{90}$ and has already been routinely monitored in UBC to investigate the lymphatics development. ${ }^{91,92}$

\section{Lymphangiogenesis And Metastasis In Bladder Cancer The VEGF-C/VEGF-D-VEGFR-3 Axis}

Lymphatics proliferation is frequently observed in bladder cancer tissue, providing an extensive communicating area and facilitating bladder cancerous cell metastasis. ${ }^{93}$ There is multistep processes involvement in the invasion and metastasis of cancer cells, including tumor cells permeate into adjacent lymphatic channels, transport tumorous cells through the lymphatic systems and plant into the distant tissues. $^{94}$ Lymphangiogenesis and lymphatic remodeling can induce cancer lymphatic metastasis by stimulating neoplastic cell invading into lymphatic vessels. However, the exact mechanism of lymphangiogenesis is unclear. ${ }^{16,95,96}$ The VEGF-C/VEGF-D-VEGFR-3 axis is seen as a major driver of tumor lymphangiogenesis, ${ }^{63}$ whereas the roles of other pathways in this process are less well defined. VEGFC/VEGF-D-VEGFR-3 pathway stimulating proliferation and migration of LECs is such as to play vital roles in lymphangiogenesis and metastasis for bladder cancer. ${ }^{97,98}$ Despite tyrosine kinase receptors, all three VEGFRs (e.g., VEGFR-1, -2 and -3) are not distributed on ECs equally. Indeed, VEGFR-1 mainly express on BECs with the feeble expression on LECs, VEGFR-3 expression is largely 
restricted to lymphatic endothelial cells contrarily, whilst VEGFR-2 could be identified both on BECs and LECs. In human bodies, five different genes encode VEGF family members such as VEGF-A, VEGF-B, VEGF-C, VEGF-D, and placenta growth factor (PlGF), respectively. According to their functions, it could be coarsely classified into two main groups, such as hematogenous factors (e.g., VEGF-A, VEGF-B, and PlGF) or lymphangiogenic factors (e.g., VEGF-C and VEGF-D). ${ }^{99,100}$ To more precisely, lymphangiogenesis can be supported by VEGFR-3 and its homologous ligands including VEGF-C and VEGF-D. Moreover, the VEGFR-3 co-receptor NRP-2 regulates the signaling pathways that are undertaken in response to VEGF-C and VEGF-D. ${ }^{101,102}$ These modes of initiating signals are somewhat analogous to the molecular modulation of angiogenesis by VEGF-A signaling via VEGFR-2 and NRP-1 ${ }^{65,103}$ (Figure 2). Proteolytic processing of VEGF-C has proved to increase its receptor affinity and biological activity. ${ }^{104}$ Recent studies have implicated that two-star molecules that are required for the development of lymphatic vessels, such as disintegrin and metalloproteinase with thrombospondin motifs 3 (ADAMTS3) protease and collagen and calcium binding EGF domains 1 (CCBE1). Some research demonstrated that an ADAMTS3-CCBE1 complex could independently form, and such complexity is required to convert VEGF-C, but not VEGF-D, into an active ligand of with no reply on VEGFR3. ${ }^{105}$ To be more specific, ADAMTS3 catalyzes the proteolytic processing of VEGF$\mathrm{C}$, removing the $\mathrm{N}$-terminal propeptide and releasing the fully active, mature VEGF-C. In vivo, ADAMTS3 could efficiently activate VEGF-C signaling in cooperation with CCBE1. CCBE1 enhances the VEGF-C activation by two different mechanisms: it increases the processivity of the ADAMTS3 enzyme, ${ }^{106}$ and it colocalizes ADAMTS3 and VEGF-C on extracellular matrix and cell surfaces to form the trimeric activation complex. ${ }^{105}$ In addition, plasmin also shows its significant roles in activating the VEGF-C and VEGF-D to induce the new formation of lymphatic

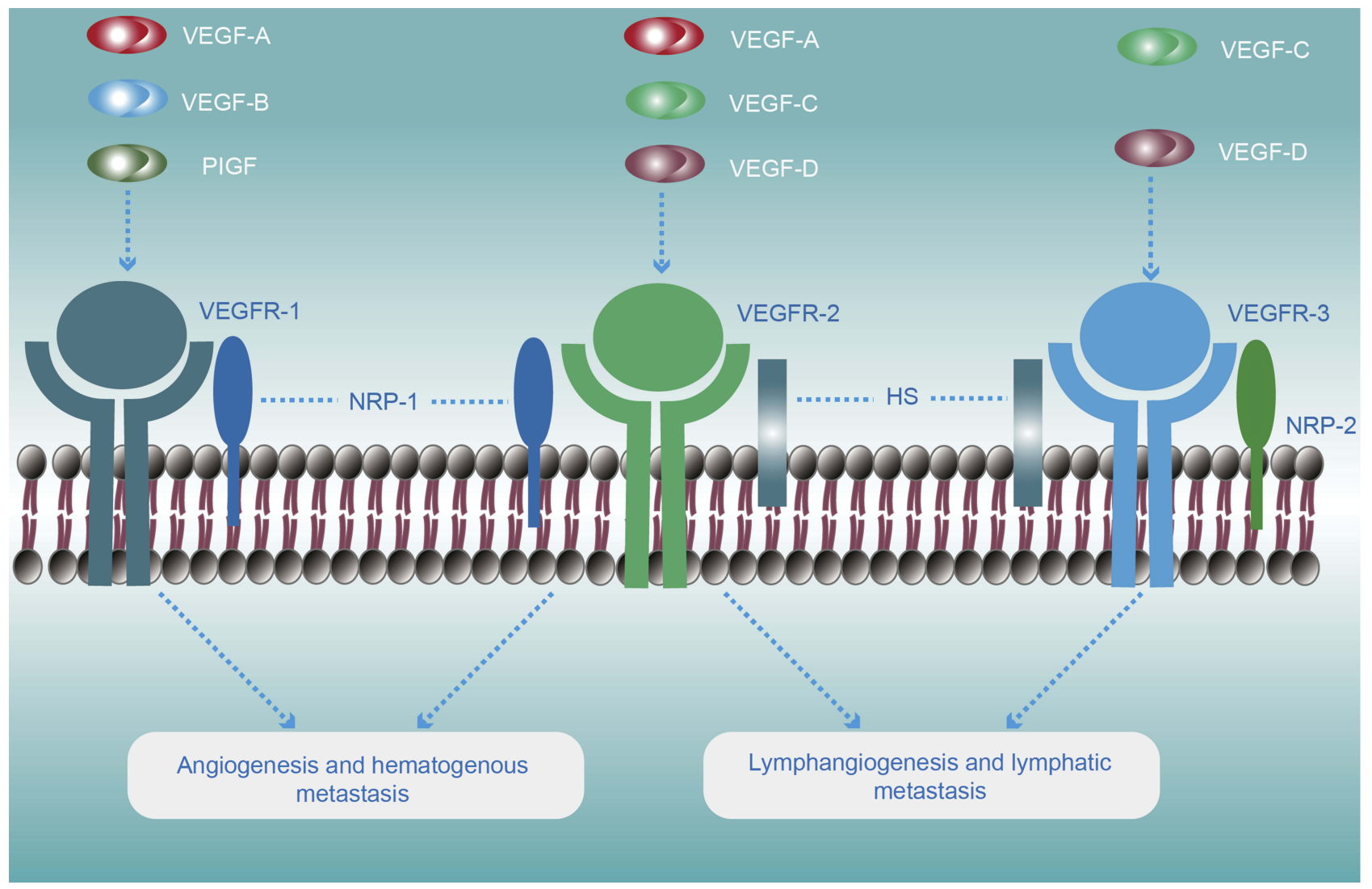

Figure 2 Schematic illustration of VEGFR structures and their specific ligands. VEGFRs are depicted as ligand-bound activated dimers. The VEGF-ligand family includes VEGFA, VEGFB, VEGFC, VEGFD, and the placenta growth factor (PIGF), which binds VEGFRs in a specific manner. VEGFB binds selectively to VEGFR-I. In contrast, VEGFA can activate VEGFR-2 and VEGFR-I, while VEGFC and VEGFD could anchor both VEGFR2 and VEGFR3 pathways. The VEGFRs co-receptors are indicated as NRP-I and NRP-2 (neuropilin-I and neuropilin-2, respectively) and HS (heparan sulfate; the main biological functions are listed below the respective receptors. In general, the VEGF-C/ VEGF-D/VEGFR-3 pathway plays a fatal role in the lymphangiogenesis and lymphatic metastasis in bladder cancer, though VEGF-C/VEGF-D/VEGFR-2 pathway may participate to some extent. 
vessels. ${ }^{107}$ After plasmin and ADAMTS3, recent research identified several novel proteases including kallikreinrelated peptidase 3 (KLK3) and cathepsin D with potential in activating of VEGF-C as well as VEGF-D to trigger the lymphangiogenesis and subsequently provide new perspectives to facilitate the development of inhibitors of cancer metastasis. ${ }^{108}$

The expression level of VEGF-C and VEGF-D is linked to $\mathrm{LN}+$ and higher LVD, showing its potential function both in LN+ and lymphangiogenesis. ${ }^{109}$ VEGF-C and VEGF-D motivate tumor cells to enter the circulatory system through enhancing tumor interstitial fluid pressure as a result of accelerating vascular leakage and lymph flow, as well increasing quantity, diameter and the proliferation rates of the LVD. ${ }^{110,111}$ When the axis is enabled, the lymphangiogenesis can be detected within and peripheral tumors, ${ }^{112}$ while the opposite outcome could be identified in some research while blocking the signaling pathway. ${ }^{113}$

\section{The Ang2/Tie-2 Pathway}

The angiopoietin system mainly includes Ang1, Ang2, and Ang4 and their receptors Tie-1 and Tie-2, and such a system has prominent impacts on endothelial cells both from the hemic and lymphatic system. Ang2, associated with tumor progression in bladder cancer, ${ }^{114}$ is most noteworthy amongst the ligands in bladder cancer concerning the lymphatic system following that in experimental tumor models. ${ }^{115}$ Moreover, Ang2 can contribute to the anatomical integrity of lymphatic systems during the embryogenesis. ${ }^{116}$

\section{The HGF/c-MET Pathway}

Hepatocyte growth factor (HGF) shows its functions in regulating resistance to anti-angiogenic therapies via changing tumor microenvironment, ${ }^{117}$ and its receptor c-Met can be isolated from the cultured lymphatic endothelial cells in vitro, and upregulated when the occurrence of inflammation and cancer in vivo, ${ }^{118}$ an indirect mechanism has also been described, mainly via activation of the VEGF-C/VEGF-D-VEGFR-3 axis. ${ }^{119}$

\section{The Shh Signaling Pathway}

In recent, the advent of the concept of cancer stem cell (CSC) has served as a novel concept for the development and progression of various tumor types, which immediately and indirectly participate in lymphangiogenesis. ${ }^{120}$ The sonic hedgehog (Shh) pathway involves the new formation of lymphatic vessels in many tumors. Some studies demonstrate that Shh signaling activates the tumor metastasis and lymphangiogenesis through waking up the AKT, EMT, and the MMP-9 pathway. ${ }^{121}$ When it now comes to UBC, Shh signaling also promotes oncogenesis and tumorigenicity, ${ }^{122}$ but its role in tumor progression is undefined. ${ }^{123}$ Some show that MIBC arises exclusively from Shh-expressing stem cells in the basal urothelium, and affirm that Shh expression is invariably lost as long as the progression to MIBC, ${ }^{124-126}$ contrarily, others argue the constitutive activation of Shh signaling. ${ }^{127}$ Cross-talks between Shh and TGF-beta may participate in the development and progression of bladder cancer as the consequence of manifesting EMT and bladder cancer stemness. ${ }^{127-129}$ Furthermore, there are several studies unravel the correlation between the CSC and Shh signaling for the tumorigenesis in bldder. ${ }^{130,131}$ A retrospective study shows that Shh pathway components are associated with lymphatic metastasis and poor clinical outcomes in bladder cancer. ${ }^{132}$ We thus hypothesize that is worth to study Shh signaling pathway to figure out underlying therapeutic values for UBC in the future.

\section{The CCL2I/CCR7 Signal Pathway}

Within most normal tissues, CCL21 mainly originates from the lymphatic system and binds to $\mathrm{C}-\mathrm{C}$ chemokine receptor 7(CCR7) selectively expressing in activated DCs in normal conditions, thereby recruiting DCs toward the lymphatic systems to perform immune responses. ${ }^{133}$ A study suggests the lymphatic flow plays a crucial role in upregulating the expression level of CCL21 of the endothelium in vitro. ${ }^{134}$ However, various tumor cells have been verified that can positively label CCR7 by activating the MEK/ERK1/2 signaling pathway instead of the PI3K/AKT pathway. ${ }^{135}$ CCR7 expression is in significant accordance with several clinicopathological parameters, including lymph node status, tumor stage, tumor grade, and overall survival in $\mathrm{BC}$ patients. ${ }^{136}$ Both VEGF axis and TGF- $\beta 1$ pathway could promote $\mathrm{CCR} 7^{+}$tumor cells migrate towards LECs via upregulated CCL21. ${ }^{137-139}$ In all, CCL21 is served as a probable carcinogenic factor due to its role in reversing the host immune response from immunogenic toward tolerogenic for $\mathrm{CCR} 7^{+}$cancer cells. ${ }^{140}$

\section{Others}

There are several kinds of RNA molecules with no proteincoding capacity, including long non-coding RNAs (lncRNAs) and microRNAs (miRNAs). The diversity of IncRNAs shows vital roles in the development and progression of human cancers, ${ }^{141}$ such as HOTAIR, SChLAP1. Moreover, 
BLACAT1 are correlated with lymphatic metastasis. ${ }^{142-144}$ Additional factors, including LINC01186 and lncRNA-ATB, participate in metastasis by inducing EMT. ${ }^{145,146} \mathrm{~A}$ recent study indicates that IncRNAs markedly upregulated in LNmetastatic bladder cancer. ${ }^{147}$ Many types of cancer are associated with aberrantly expressing of miRNAs, ${ }^{148}$ such as miR128 downregulation promotes lymphangiogenesis and metastasis of UBC by the upregulation of VEGF-C. ${ }^{149}$ In addition to these that we have discussed above, multiple other growth factors and their receptors such as platelet-derived growth factor(PDGF)/PDGFR, fibroblast growth factor(FGF)-2/ FGFR, epidermal growth factor(EGF)/EGFR and insulin-like growth factor(IGF)/IGFR involve with lymphangiogenesis under various circumstances, indirectly or directly. ${ }^{64,65,150-153}$

\section{Therapeutics Aimed At Lymphangiogenesis And Lymphatic Metastasis}

Nowadays, the first-line treatment for malignant MIBC is radical cystectomy with extensive pelvic lymphadenectomy, whereas a quarter of those patients undergoing radical cystectomy for MIBC show $\mathrm{Ln}+{ }^{154}$ Nowadays, $\mathrm{Ln}+$ is one of the most important predictors for the outcomes in individuals with bladder cancer. Cisplatin-based regimens have already regarded as the standard first-line chemotherapy since the late 1980s, including the use of including MVAC (methotrexate, vinblastine, adriamycin, and cisplatin) and GC (gemcitabine and cisplatin), and the survival of patients with metastatic urothelial carcinoma has yet remained rather poor. ${ }^{6}$ Many studies demonstrate that the inhibition of the lymphangiogenic signaling pathway might restrict metastasis to lymph nodes and potentially to distant organs in various tumors, including urothelial carcinoma as well. Indeed, targeting tumor-associated lymphangiogenesis could be a feasible molecular target for patients with bladder cancer. The most studied biological pathway is VEGF-C/VEGF-D-VEGFR-3 axis, and such signaling is the important biological signaling pathway for lymphangiogenesis and lymphatic metastasis in tumors. As a consequence, inhibition of VEGF-C/VEGF-D/VEGFR-3 recognizes a potential way to restrain tumor progression. ${ }^{155-157}$ Currently, the antibody of VEGF-C and its receptor antibody- VEGFR-3, such as VGX-100 ${ }^{158}$ and IMC-3C $5,{ }^{159}$ respectively, have entered clinical testing for the treatment of cancer. In addition, blocking the VEGFR-2 also shows potential in diminishing the lymphatic metastasis. ${ }^{160}$ Assorted other small-molecule antibodies and protein kinase inhibitors, under clinical trials and preclinical stages, ${ }^{39,161-164}$ that target VEGF-C/VEGF-D-VEGFR-3 are shown in details in Table 1. Another signaling axis, such as the HGF-c-MET ${ }^{165-168}$ and Ang2-Tie-2 ${ }^{169-171}$ pathway, may serve also as targets to inhibit lymphangiogenesis by specific antibodies (Table 1). Several antibodies and antibody formats such as Sorafenib, ${ }^{172}$ Pazopanib, ${ }^{173}$ Sunitinib, ${ }^{174,175}$ Axitinib, ${ }^{176}$ Regorafenib, ${ }^{177}$ Vatalanib ${ }^{178}$ have been extensively applied for cancer treatment in the clinic, could decline peritumoral LVD and lower the incidence of lymph node metastasis via inhabitation of various signaling pathways. Other potentially useful reagents, including neutralizing mAbs to NRP $2{ }^{179}$ and COX enzymes, ${ }^{180,181}$ are also in undergoing investigation, with showing potential therapeutic targets. However, it remains not clear as to when such drugs should be ideally offered to tumor patients to restrain carcinoma spreading. It is warranted to develop novel technology for patient selection pre-treatment, or prognosis surveillance after gave such anti-lymphangiogenic therapy. Immuno-positron emission tomography (I-PET) with lymphatic-specific antibodies, a new imaging approaches, may eke out from such assignable issues in the clinic. ${ }^{182}$

Cancer immunotherapy encompasses all the methods sought to facilitate the identification and eradication of cancerous cells by the aid of the immune system. Indeed, immunotherapies (e.g., BCG, CTLA-4, and PD-1/PD-L1) have revolutionized the treatment paradigm in urothelial carcinoma of the bladder, especially for the patients eventually develop resistance to this standard first-line treatments. ${ }^{183,184}$ Booming evidence highlight that, aside from transport and trafficking functions, tumor-associated lymphatics further represent a conceivable role in shaping antitumor immunity. In particular, tumor-associated lymphatic vessels are initially required for the recruitment of immunocyte and the initiation of the adaptive immune response. Indeed, numerous investigations suggest that neoplasm drainage, dendritic cells trafficking, and subsequent activation of anti-tumor specific $\mathrm{T}$ cell responses is remarkably disturbed in transgenic mice with impaired or lacking local lymphatic vessels. ${ }^{185,186}$ Antigens transport by dendritic cells via lymphatic vessels toward draining LNs is indispensable for the activation of anti-tumor adaptive immune responses, and thus indicate that develop LNs- or LVs-targeting approaches, including indirect targeting of draining LNs by the usage of drug delivery systems with optimal lymphatic retention and uptake properties, and the direct injection of immunomodulatory agents into cutaneous LNs or lymphatics, are potential therapeutics to impair malignancies progression and 
Table I Overview Of Potential Drugs Which Target Lymphangiogenic Pathways

\begin{tabular}{|c|c|c|c|c|}
\hline Target & Drug Name & Description & Status & $\begin{array}{l}\text { NCT Or Ref } \\
\text { Number }\end{array}$ \\
\hline VEGF-C & VGX-100 & VEGF-C blocking antibody & Phase I ongoing & NCTOI5I4I23 \\
\hline \multirow[t]{2}{*}{ VEGF-D } & VDI & Monoclonal antibodies & Preclinical & 161,162 \\
\hline & CVEI99 & Monoclonal antibodies & Preclinical & 163 \\
\hline VEGF-C and VEGF-D & VGX-300 & Soluble VEGFR3 construct & Preclinical & 39 \\
\hline $\begin{array}{l}\text { VEGF-C, VEGF-D, and } \\
\text { VEGF-A }\end{array}$ & sVEGFR2 & Soluble VEGFR2 construct & Preclinical & 164 \\
\hline \multirow[t]{5}{*}{ VEGFR-3 } & IMC-3C5/hF4-3C5 & $\begin{array}{l}\text { VEGFR-3 blocking monoclonal } \\
\text { antibody }\end{array}$ & Phase I completed & NCTOI288989 \\
\hline & Sorafenib & Small-molecule PKI & Approved for clinical applicant & 172 \\
\hline & Pazopanib & Small-molecule PKI & Approved for clinical applicant & 173 \\
\hline & Sunitinib & Small-molecule PKI & Approved for clinical applicant & 174,175 \\
\hline & Axitinib & Small-molecule PKI & Approved for clinical applicant & 176 \\
\hline \multirow[t]{2}{*}{ VEGFR-3 and TIE2 } & Regorafenib & Small-molecule PKI & Approved for clinical applicant & 177 \\
\hline & CEP-II98I & Small-molecule PKI & Phase I completed & NCT00875264 \\
\hline \multirow[t]{14}{*}{ c-MET } & AMG337 & Small molecule c-MET inhibitor & Phase I completed Phase 2 terminated & $\begin{array}{l}\text { NCT0I } 253707 \\
\text { NCT020I6534 }\end{array}$ \\
\hline & AMG 208 & Small molecule c-MET inhibitor & Phase I completed Phase 2 terminated & $\begin{array}{l}\text { NCT008I3384 } \\
\text { NCT02420587 }\end{array}$ \\
\hline & Crizotinib & $\begin{array}{l}\text { Small molecule c-MET, } \\
\text { ROSI and ALK }\end{array}$ & Phase 2 ongoing & NCT0203498I \\
\hline & PF-04217903 & $\begin{array}{l}\text { c-MET/HGFR tyrosine kinase } \\
\text { inhibitors }\end{array}$ & Phasel completed & NCT00706355 \\
\hline & Capmatinib (INC280) & Small molecule c-MET inhibitor & Phase I completed & NCT02626234 \\
\hline & $\begin{array}{l}\text { Tepotinib } \\
\text { (MSC2156II9J) }\end{array}$ & Small molecule c-MET inhibitor & Phase I completed & NCT0I 832506 \\
\hline & $\begin{array}{l}\text { Foretinib (GSKI363089 } \\
\text { and XL 880) }\end{array}$ & $\begin{array}{l}\text { Small molecule c-MET/HGFR } \\
\text { inhibitors }\end{array}$ & Phase 2 completed & NCT00726323 \\
\hline & Tivantinib (ARQ 197) & Small molecule c-MET inhibitor & Phase 2 ongoing & NCT0I 892527 \\
\hline & ARGX III & antibody blocking c-MET & Phase I completed & NCT02055066 \\
\hline & EMD I20483| & c-Met kinase Inhibitor & Phase I terminated & NCTOIII 0083 \\
\hline & ABT-70 (ABBV-399) & $\begin{array}{l}\text { anti-c-Met monoclonal } \\
\text { antibody }\end{array}$ & Phase 2 ongoing & NCT03574753 \\
\hline & Volitinib (HMPL-504) & $\begin{array}{l}\text { small molecule inhibitor of c- } \\
\text { Met kinase }\end{array}$ & Phase I completed & NCT0I773018 \\
\hline & $\begin{array}{l}\text { Onartuzumab } \\
\text { (MetMAb) }\end{array}$ & $\begin{array}{l}\text { Monovalent, c-MET blocking } \\
\text { antibody }\end{array}$ & Phase 3 completed & NCTOI 887886 \\
\hline & SAIT30I & monoclonal antibody of c-MET & Phase I completed & NCT02296879 \\
\hline
\end{tabular}

(Continued) 
Table I (Continued).

\begin{tabular}{|c|c|c|c|c|}
\hline Target & Drug Name & Description & Status & $\begin{array}{l}\text { NCT Or Ref } \\
\text { Number }\end{array}$ \\
\hline \multirow[t]{3}{*}{ EFG } & YYBIOI & HGF neutralizing antibody & Phase I ongoing & NCT02499224 \\
\hline & Ficlatuzumab (AV-299) & HGF neutralizing antibody & Phase I ongoing & NCT03316599 \\
\hline & $\begin{array}{l}\text { Rilotumumab } \\
\text { (AMG I02) }\end{array}$ & HGF neutralizing antibody & Phase 3 terminated & NCT02I37343 \\
\hline \multirow[t]{5}{*}{ Angl/Ang2 } & AMG 386 (Trebananib) & sequestering AngI and Ang2 & Phase 3 terminated & NCTOI $28 \mid 254$ \\
\hline & $C V X-060$ & $\begin{array}{l}\text { Anti-angiogenic Covx-body } \\
\text { Binding Ang2 }\end{array}$ & Phase I completed & NCT00879684 \\
\hline & $C V X-241$ & $\begin{array}{l}\text { Ang2/VEGF neutralizing } \\
\text { bisprecific CovX-body }\end{array}$ & Phase I completed & NCTOI004822 \\
\hline & REGN9I0-3 & Ang2 neutralizing antibody & Phase I completed & NCT027I 3204 \\
\hline & AMG780 & $\begin{array}{l}\text { Angl/Ang2 neutralizing } \\
\text { antibody }\end{array}$ & Phase I terminated & NCTOII 37552 \\
\hline \multirow[t]{5}{*}{ TIE2 } & ARRY-6I4 & p38/Tie2 inhibitor & Phase I completed & NCT0I496495 \\
\hline & $\begin{array}{l}\text { Regorafenib } \\
\text { (BAY 73-4506) }\end{array}$ & Tie2 inhibitor & Phase 3 ongoing & NCT02773524 \\
\hline & DCC-2036 & Tie2 inhibitor & Phase I completed & NCT00827I38 \\
\hline & CEP-II98I (ESK98I) & $\begin{array}{l}\text { VEGFR/TIE2 tyrosine kinase } \\
\text { inhibitor }\end{array}$ & Phase I ongoing & NCT03456804 \\
\hline & AMG-386 & Neutralizing peptibody & Phase 2 completed & NCTOI 290263 \\
\hline NRP2 & Anti-NRP2B & Monoclonal antibody & Preclinical & 179 \\
\hline $\operatorname{cox} 2$ & NSAIDs & Small molecules & $\begin{array}{l}\text { Approved for use as analgesics and as anti- } \\
\text { inflammatory agents }\end{array}$ & 180,181 \\
\hline
\end{tabular}

Abbreviations: VEGF, vascular endothelial growth factor; PKI, protein kinase inhibitor; c-Met, tyrosine-protein kinase Met; HGFR, hepatocyte growth factor receptor; EFG, epidermal growth factor; Ang: angiotensin; TIE2, tyrosine kinase with immunoglobulin-like and EGF-like domains; NRP2, neuropilin 2; COX2, cyclooxygenase; NSAID: non-steroidal anti-inflammatory drug.

metastasis, which that are not discussed in there, readers can review in detail in several published review articles for these topics. ${ }^{187-189}$ However, lymphatic endothelial cells, the initial components of lymphatic vessels, undergo active modifications that facilitate metastatic dissemination and can have direct interactions with immune cells (e.g., DCs and T cells) to negatively induce immunoregulation. To more specific, direct LEC-T cell interactions and antigen presentation to dendritic cells can induce the dysfunctional $\mathrm{CD} 8+\mathrm{T}$ cell activation or the $\mathrm{CD} 4+\mathrm{T}$ cell apoptosis, ${ }^{187}$ or lymphatic endothelial cells produce several biological factors(e.g., IDO, MHCs, and NO) that indirectly aid in the maintenance of regulatory $\mathrm{T}$ cell populations and impairment of DCs maturation and $\mathrm{T}$ cell activation. ${ }^{190-192}$ Thus, anchoring the LECs to manipulate immune responses open opportunities for therapeutic targeting in the cancer treatment paradigm. Additional research will need to determine how to selectively target LEC immunosuppressive functions in cancers, which could, combined with immunotherapeutic methods, facilitate the evolvement of a "cold" into "hot" immunogenic TME and potentiate anti-tumor $\mathrm{T}$ cell responses. The current clinical trial researches targeting at lymphatic metastasis involving cancers, and the above studies demonstrate that biological processes of lymphangiogenesis and anti-lymphangiogenesis involve multiple pathways. When one signaling pathway is inhibited, others may make compensation for its absence. Therefore, future anti-lymphatic treatment therapy may be complex involving inhibitors of diverse pathways. 


\section{Discussions}

Over the past decades, tumor-associated lymphangiogenesis has been thought to be a new target to eliminate metastatic malignancy. To date, the development of specific anti-lymphangiogenic drugs has reached the stage of clinical trials. Nevertheless, much remains to be done: Primarily, the molecular mechanisms that govern the entry of tumorous cells into remodeled or newly-born lymphatic vessels-be their ITLs or PTLs-have not been comprehensively characterized; Second, it is unclear whether remodeling of lymphatics and/ or the tumor-associated lymphangiogenesis are crucially required for the carcinoma dissemination to LNs or distant organs; Third, the degree to which LN metastases directly contribute to distant organ metastasis needs to be defined, as do the mechanisms through which this may occur; In addition, as mention above part, LVs play a dual role in tumor immunity; therefore, LV might display positive and/or negative effects on tumor immunity depending on the stage of tumor progression and on the immunological settings (immune evasion/immune subversion or immunotherapy). It is thus urgent to decipher precisely the roles for LVs in tumor cell dissemination and anti-tumor $\mathrm{T}$ cell immunity; Furthermore, novel imaging methods and whole-genome functional screens with LECs are needed to monitor the efficiency of anti-lymphangiogenesis drugs accurately, and to provide precise treatment for those patients who can get more benefits from these treatments; Additionally, anti-lymphangiogenic therapy may enhance interstitial fluid pressure and hamper drug delivery to cancerous cells. ${ }^{193}$ Consistently with tumor angiogenesis, variety of lymphangiogenic pathways and hundreds of regulatory molecules involve the new formation of lymphatic vessels within TMEs, meaning that single pathway targeting drugs might not be efficient in all cases. Thereby, investigations into the optimal scheduling of combination therapies are needed.

\section{Conclusions}

Increasing clinical studies show the evidence that lymphatic vessel invasion and lymph node metastasis depict poor prognosis indicators in UBC. As already discussed, the GEP platform could analyze the relationships between tens of thousands candidate genes and lymph node involvement at a given time with the help of Next-Generation Sequencing and Biotechnology; however, GEP technology is limited due to unable to detect the interactions or signaling crosstalk. More investigations are also required to identify the genes associated with poor prognosis profiles, which could protect the patient against suffering poor prognosis via aiding in rational clinical decision-making during the earlier status. Over the past few decades, the great efforts have been made in elucidating the cellular and molecular mechanisms underlying lymphatic metastasis, especially the discovery of lymphangiogenic growth factors and specific biomarkers of LECs and development of GEM, making profound breakthroughs to unravel the complexity of the lymphatic metastatic process. Currently, the VEGFC/VEGF-D-VEGFR-3 pathway is correlated with the tumor-derived lymphatic vessels and metastasis in UBC, blocking such signaling pathway suppresses tumor lymphangiogenesis. Research into the lymphatic system is currently undergoing another revolution about the real-time imaging of lymphatic metastasis, for instance, to develop a new, noninvasive in vivo imaging techniques contribute to detect metastases to evaluate the scope of surgery based on the identification of tumor-induced stromal changes, which mainly relies on the specific biomarkers. Owing to its complexity, the existing molecular mechanisms remain yet controversial. In the future, therefore, large-scale basic research and a grand mass of clinical specimens are in importance for developing further accurate molecules. Novel antitumor drugs targeting the newly identified molecular markers or pathway can then be put into place to prevent bladder cancer metastasis at an earlier stage and provide better outcomes for bladder cancer patients.

\section{Abbreviations}

UBC, urinary bladder cancer; NMIBC, non-muscle invasive bladder cancer; MIBC, muscle-invasive bladder cancer; LNs, lymph nodes; LEC, lymphatic endothelial; GEM, Gene expression models; MMP-2, matrix metalloproteinase-2; LVD, lymphatic vessels density; VEGF, vascular endothelial growth factor; PROX-1, prospero-related homeobox-1; COX-2, cyclooxygenase-2; EMT, epithelialmesenchymal transition; HGF, hepatocyte growth factor; CSC, cancer stem cell; Shh, sonic hedgehog; DCs, dendritic cells; CCR7, C-C chemokine receptor 7; CCL21, chemokine (C-C motif) ligand 21; lncRNAs, long noncoding RNAs; miRNAs, microRNAs. SOX-18, SRY-related HMG-box-18, MAFB, musculoaponeurotic fibrosarcoma oncogene homolog B; MAPK, mitogen-activated protein kinase; ERK, extracellular signal-regulated kinase; COUPTF-2, COUP transcription factor-2; NR2F-2, nuclear receptor subfamily 2 group $\mathrm{F}$ member 2; PI3K, phosphatidylinositol 3-kinase; PKB, protein kinase B; NRP-2, neuropilin 2. 


\section{Acknowledgment}

We gratefully acknowledge the help of staff at the Department of Urology of the Third Affiliated Hospital of Shenzhen University with data analysis.

\section{Author Contributions}

All authors contributed towards data analysis, drafting and critically revising the paper, gave final approval of the version to be published, and agreed to be accountable for all aspects of the work.

\section{Funding}

This work was financially supported by a scholarship from The National Key Research and Development Program of China (No. 2017YTA0105900), The National Natural Science Foundation Fund of China (81672533), and the Shenzhen Basic Research Project (JCYJ20160429172247015; JCYJ20 160429093033251).

\section{Disclosure}

The authors report no conflicts of interest in this work.

\section{References}

1. Siegel RL, Miller KD, Jemal A. Cancer statistics, 2016. CA Cancer J Clin. 2016;66(1):7-30. doi:10.3322/caac.21332

2. Antoni S, Ferlay J, Soerjomataram I, et al. Bladder cancer incidence and mortality: a global overview and recent trends. Eur Urol. 2017;71(1):96-108.

3. Miyata Y, Kanda S, Mitsunari K, et al. Heme oxygenase-1 expression is associated with tumor aggressiveness and outcomes in patients with bladder cancer: a correlation with smoking intensity. Transl Res. 2014;164(6):468-476.

4. Nawaz K, Webster RM. The bladder cancer drug market. Nat Rev Drug Discov. 2016;15(9):599-600.

5. $\mathrm{Xu} \mathrm{X}$, Chen $\mathrm{H}$, Lin $\mathrm{Y}$, et al. MicroRNA-409-3p inhibits migration and invasion of bladder cancer cells via targeting c-Met. Mol Cells. 2013;36(1):62-68.

6. Babjuk M, Bohle A, Burger M, et al. EAU guidelines on nonmuscle-invasive urothelial carcinoma of the bladder: update 2016. Eur Urol. 2017;71(3):447-461.

7. Sun M, Trinh QD. Diagnosis and staging of bladder cancer. Hematol Oncol Clin North Am. 2015;29(2):205-218, vii.

8. Seisen T, Peyronnet B, Dominguez-Escrig JL, et al. Oncologic outcomes of kidney-sparing surgery versus radical nephroureterectomy for upper tract urothelial carcinoma: a systematic review by the EAU non-muscle invasive bladder cancer guidelines panel. Eur Urol. 2016;70(6):1052-1068.

9. Matsushita R, Seki N, Chiyomaru T, et al. Tumour-suppressive microRNA-144-5p directly targets CCNE1/2 as potential prognostic markers in bladder cancer. Br J Cancer. 2015;113(2):282-289.

10. Meeks JJ, Bellmunt J, Bochner BH, et al. A systematic review of neoadjuvant and adjuvant chemotherapy for muscle-invasive bladder cancer. Eur Urol. 2012;62(3):523-533. doi:10.1016/j.eururo.2012. 05.048
11. Itesako $\mathrm{T}$, Seki $\mathrm{N}$, Yoshino $\mathrm{H}$, et al. The microRNA expression signature of bladder cancer by deep sequencing: the functional significance of the miR-195/497 cluster. PLoS One. 2014;9(2): e84311. doi:10.1371/journal.pone.0084311

12. Aljabery F, Shabo I, Olsson H, Gimm O, Jahnson S. Radio-guided sentinel lymph node detection and lymph node mapping in invasive urinary bladder cancer: a prospective clinical study. BJU Int. 2017;120(3):329-336. doi:10.1111/bju.2017.120.issue-3

13. Afonso J, Santos LL, Amaro T, et al. The aggressiveness of urothelial carcinoma depends to a large extent on lymphovascular invasion-the prognostic contribution of related molecular markers. Histopathology. 2009;55(5):514-524. doi:10.1111/j.1365-2559.2009.03425.x

14. Gupta GP, Massague J. Cancer metastasis: building a framework. Cell. 2006;127(4):679-695. doi:10.1016/j.cell.2006.11.001

15. Cao Y. Opinion: emerging mechanisms of tumour lymphangiogenesis and lymphatic metastasis. Nat Rev Cancer. 2005;5(9):735-743. doi: $10.1038 / \mathrm{nrc} 1693$

16. Karaman S, Detmar M. Mechanisms of lymphatic metastasis. $J$ Clin Invest. 2014;124(3):922-928. doi:10.1172/JCI71606

17. Siegel R, Ma J, Zou Z, et al. Cancer statistics, 2014. CA Cancer J Clin. 2014;64(1):9-29.

18. Kluth LA, Black PC, Bochner BH, et al. Prognostic and prediction tools in bladder cancer: a comprehensive review of the literature. Eur Urol. 2015;68(2):238-253.

19. Orsola A, Werner L, De TI, et al. Reexamining treatment of highgrade T1 bladder cancer according to depth of lamina propria invasion: a prospective trial of 200 patients. $\mathrm{Br} J$ Cancer. 2015;112(3):468-474.

20. Tammela T, Alitalo K. Lymphangiogenesis: molecular mechanisms and future promise. Cell. 2010;140(4):460-476.

21. Leu AJ, Berk D, Lymboussaki A, et al. Absence of functional lymphatics within a murine sarcoma: a molecular and functional evaluation. Cancer Res. 2000;60:4324-4327.

22. Padera TP, Kadambi A, di Tomaso E, al: E. Lymphatic metastasis in the absence of functional intratumor lymphatics. Science. 2002;296(5574):1883-1886.

23. Adamczyk LA, Gordon K, Kholova I, et al. Lymph vessels: the forgotten second circulation in health and disease. Virchows Arch. 2016;469(1):3-17.

24. Karpanen T, Alitalo K. Molecular biology and pathology of lymphangiogenesis. Annu Rev Pathol. 2008;3:367-397.

25. Wigle JT, Harvey N, Detmar M, et al. An essential role for Prox1 in the induction of the lymphatic endothelial cell phenotype. Embo J. 2002;21(7):1505-1513.

26. François M, Caprini A, Hosking B, et al. Sox18 induces development of the lymphatic vasculature in mice. Nature. 2008;456:643.

27. Karkkainen MJ, Haiko P, Sainio K, et al. Vascular endothelial growth factor $\mathrm{C}$ is required for sprouting of the first lymphatic vessels from embryonic veins. Nat Immunol. 2004;5(1):74-80.

28. Escobedo N, Oliver G. Lymphangiogenesis: origin, specification, and cell fate determination. Annu rev cell dev biol. 2016;32:677-691.

29. Semo J, Nicenboim J, Yaniv K. Development of the lymphatic system: new questions and paradigms. Development. 2016;143:924-935.

30. Wong B, Zecchin A, García-Caballero M, et al. Emerging concepts in organ-specific lymphatic vessels and metabolic regulation of lymphatic development. Dev Cell. 2018;45:289-301.

31. Duong T, Koltowska K, Pichol-Thievend C, et al. VEGFD regulates blood vascular development by modulating SOX18 activity. Blood. 2013;123(7):1102-1112.

32. Deng Y, Atri D, Eichmann A, et al. Endothelial ERK signaling controls lymphatic fate specification. J Clin Invest. 2013;123 (3):1202-1215. 
33. Hong Y-K, Harvey N, Noh Y-H, et al. Prox1 is a master control gene in the program specifying lymphatic endothelial cell fate. Dev Dyn. 2002;225:351-357.

34. Petrova TV, Mäkinen T, Mäkelä TP, et al. Lymphatic endothelial reprogramming of vascular endothelial cells by the Prox-1 homeobox transcription factor. Embo J. 2002;21(17):4593-4599.

35. Kim H, Nguyen VP, Petrova TV, et al. Embryonic vascular endothelial cells are malleable to reprogramming via Prox1 to a lymphatic gene signature. BMC Dev Biol. 2010;10:72.

36. Johnson NC, Dillard M, Baluk P, et al. Lymphatic endothelial cell identity is reversible and its maintenance requires Prox 1 activity. Genes Dev. 2009;22:3282-3291.

37. Sathish Srinivasan R, Escobedo N, Yang Y, et al. The Prox1-vegfr3 feedback loop maintains the identity and the number of lymphatic endothelial cell progenitors. Genes Dev. 2014;28:2175-2187.

38. Karkkainen MJ, Haiko P, Sainio K, et al. Vascular endothelial growth factor $\mathrm{C}$ is required for sprouting of the first lymphatic vessels from embryonic veins. Nat Immunol. 2004;5:74-80.

39. Mäkinen T, Jussila L, Veikkola T, et al. Inhibition of lymphangiogenesis with resulting lymphedema in transgenic mice expressing soluble VEGF receptor-3. Nat Med. 2001;7(2):199-205.

40. Fatima A, Wang Y, Uchida Y, et al. Foxc1 and Foxc2 deletion causes abnormal lymphangiogenesis and correlates with ERK hyperactivation. J Clin Insight. 2016;126:2437-2451.

41. Baluk P, Fuxe J, Hashizume H, et al. Functionally specialized junctions between endothelial cells of lymphatic vessels. $J \operatorname{Exp}$ Med. 2007;204:2349-2362.

42. Gerli R, Solito R, Weber E, et al. Specific adhesion molecules bind anchoring filaments and endothelial cells in human skin initial lymphatics. Lymphology. 2001;33:148-157.

43. Baluk P, Fuxe J, Hashizume H, et al. Functionally specialized junctions between endothelial cells of lymphatic vessels. $J$ Exp Med. 2007;204(10):2349-2362.

44. Ulvmar MH, Mäkinen T. Heterogeneity in the lymphatic vascular system and its origin. Cardiovasc Res. 2016;111(4):310-321.

45. Alitalo A, Detmar M. Interaction of tumor cells and lymphatic vessels in cancer progression. Oncogene. 2012;31(42):4499-4508.

46. Farnsworth R, Achen MG, Stacker SS. The evolving role of lymphatics in cancer metastasis. Curr Opin Immunol. 2018;53:64-73.

47. Levick JR, Michel CC. Microvascular fluid exchange and the revised starling principle. Cardiovasc Res. 2010;87(2):198-210.

48. Sleeman J, Steeg PS. Cancer metastasis as a therapeutic target. Eur $J$ Cancer. 2010;46(7):1177-1180.

49. Bolenz C, Auer M, Ströbel P, et al. The lymphatic system in clinically localized urothelial carcinoma of the bladder: morphologic characteristics and predictive value. Urol Oncol 2012;31:16061614.

50. Ji RC, Eshita Y, Kato S. Investigation of intratumoural and peritumoural lymphatics expressed by podoplanin and LYVE-1 in the hybridomainduced tumours. Int J Exp Pathol. 2007;88(4):257-270.

51. Williams CS, Leek RD, Robson AM, et al. Absence of lymphangiogenesis and intratumoural lymph vessels in human metastatic breast cancer. J Pathol. 2003;200(2):195-206.

52. Wong SY, Haack H, Crowley D, et al. Tumor-secreted vascular endothelial growth factor-C is necessary for prostate cancer lymphangiogenesis, but lymphangiogenesis is unnecessary for lymph node metastasis. Cancer Res. 2005;65(21):9789-9798.

53. Ji RC. Lymphatic endothelial cells, tumor lymphangiogenesis and metastasis: new insights into intratumoral and peritumoral lymphatics. Cancer Metastasis Rev. 2006;25(4):677-694.

54. Ma Y, Hou Y, Liu B, et al. Intratumoral lymphatics and lymphatic vessel invasion detected by D2-40 are essential for lymph node metastasis in bladder transitional cell carcinoma. Anat Rec (Hoboken). 2010;293 (11):1847-1854.
55. Bolenz C, Auer M, Strobel P, et al. The lymphatic system in clinically localized urothelial carcinoma of the bladder: morphologic characteristics and predictive value. Urol Oncol. 2013;31(8):1606-1614.

56. Dancik G, Aisner D, Theodorescu D. A 20 gene model for predicting nodal involvement in bladder cancer patients with muscle invasive tumors. PLoS Curr. 2011;3:RRN1248.

57. Seiler R, Lam LL, Erho N, et al. Prediction of lymph node metastasis in bladder cancer patients using whole transcriptome gene expression signatures. J Urol. 2016;196(4):1036-1041.

58. Smith SC, Baras AS, Dancik G, et al. A 20-gene model for molecular nodal staging of bladder cancer: development and prospective assessment. Lancet Oncology. 2011;12(2):111-112.

59. Kessel KV, Werken HVD, Lurkin I, et al. 20-gene expression signature to predict lymph node positive disease at radical cystectomy for muscle-invasive bladder cancer: not validated. Eur Urol Suppl. 2017;16(3):e460-e461.

60. Wang B, Wan F, Sheng H, et al. Identification and validation of an 18-gene signature highly-predictive of bladder cancer metastasis. Sci Rep. 2018;8(1):374.

61. Wu SX, Huang J, Liu ZW, et al. A genomic-clinicopathologic nomogram for the preoperative prediction of lymph node metastasis in bladder cancer. EBioMedicine. 2018;31:54-65.

62. Lindquist KJ, Sanford T, Friedlander TW, et al. Copy number gains at chr3p25 and chr11p11 are associated with lymph node involvement and survival in muscle-invasive bladder tumors. PLoS One. 2017;12(11):e0187975.

63. Tammela T, Alitalo K, Tammela T. Alitalo KLymphangiogenesis: molecular mechanisms and future promise. Cell. 2010;140:460476.

64. Koltowska K, Betterman KL, Harvey NL, et al. Getting out and about: the emergence and morphogenesis of the vertebrate lymphatic vasculature. Development. 2013;140:1857-1870.

65. Stacker S, Williams SP, Karnezis T, et al. Lymphangiogenesis and lymphatic vessel remodelling in cancer. Nat Rev. 2014;14:159-172.

66. Dicken B, Graham K, Hamilton SM, et al. Lymphovascular invasion is associated with poor survival in gastric cancer: an application of gene-expression and tissue array techniques. Ann surg 2006;243:64-73.

67. Alexander-Sefre F, Nibbs R, Rafferty T, et al. Clinical value of immunohistochemically detected lymphatic and vascular invasions in clinically staged endometrioid endometrial cancer. Int $J$ Gynecologic Cancer. 2009;19:1074-1079.

68. Weiser MR, Landmann R, Kattan M, et al. Individualized prediction of colon cancer recurrence using a nomogram. J Clin Oncol. 2008;26:380-385.

69. Shariat S, Khoddami SM, Saboorian H, et al. Lymphovascular invasion is a pathological feature of biologically aggressive disease in patients treated with radical prostatectomy. J Urol. 2004;171:1122-1127.

70. Straume O, Jackson DG, Akslen LA. Independent prognostic impact of lymphatic vessel density and presence of low-grade lymphangiogenesis in cutaneous melanoma. Clin Cancer Res. 2003;9(1):250-256.

71. Xu S, Yang J, Xu S, et al. Lymphatic vessel density as a prognostic indicator in Asian NSCLC patients: a meta-analysis. BMC Pulm Med. 2018;18.

72. Zhang $\mathrm{S}$, Yi S, Zhang $\mathrm{D}$, et al. Intratumoral and peritumoral lymphatic vessel density both correlate with lymph node metastasis in breast cancer. Sci rep 2017;7:40364.

73. Algaba F. Lymphovascular invasion as a prognostic tool for advanced bladder cancer. Curr Opin Urol. 2006;16:367-371.

74. Mathieu R, Lucca I, Roupret M, et al. The prognostic role of lymphovascular invasion in urothelial carcinoma of the bladder. Nat Rev Urol. 2016;13. 
75. Yang H, Kim C, Kim MJ, et al. Soluble vascular endothelial growth factor receptor-3 suppresses lymphangiogenesis and lymphatic metastasis in bladder cancer. Mol Cancer. 2011;10(1):36.

76. Miyata Y, Kanda S, Ohba K, et al. Lymphangiogenesis and angiogenesis in bladder cancer: prognostic implications and regulation by vascular endothelial growth factors-A, -C, and -D. Clin Cancer Res. 2006;12(3 Pt 1):800-806.

77. Lopez de Cicco R, Watson JC, Bassi DE, et al. Simultaneous expression of furin and vascular endothelial growth factor in human oral tongue squamous cell carcinoma progression. Clin Cancer Res. 2004;10(13):4480-4488.

78. White JD, Hewett PW, Kosuge D, et al. Vascular endothelial growth factor-D expression is an independent prognostic marker for survival in colorectal carcinoma. Cancer Res. 2002;62(6):16691675 .

79. Ogawa E, Takenaka K, Yanagihara K, et al. Clinical significance of VEGF-C status in tumour cells and stromal macrophages in nonsmall cell lung cancer patients. Br J Cancer. 2004;91(3):498-503.

80. Yuan L, Moyon D, Pardanaud L, et al. Abnormal lymphatic vessel development in neuropilin 2 mutant mice. Development. 2002;129 (20):4797-4806.

81. Karpanen T, Heckman CA, Keskitalo S, et al. Functional interaction of VEGF-C and VEGF-D with neuropilin receptors. Faseb J. 2006;20(9):1462-1472.

82. Banerji S, Ni J, Wang SX, et al. LYVE-1, a new homologue of the CD44 glycoprotein, is a lymph-specific receptor for hyaluronan. $J$ Cell Biol. 1999;144(4):789-801.

83. Wigle JT, Oliver G. Prox 1 function is required for the development of the murine lymphatic system. Cell. 1999;98(6):769-778.

84. Castro EC, Galambos C. Prox-1 and VEGFR3 antibodies are superior to D2-40 in identifying endothelial cells of lymphatic malformations-a proposal of a new immunohistochemical panel to differentiate lymphatic from other vascular malformations. Pediatr Dev Pathol. 2009;12(3):187-194.

85. Mishima K, Watabe T, Saito A, et al. Prox 1 induces lymphatic endothelial differentiation via integrin $\alpha 9$ and other signaling cascades. Mol Biol cell. 2007;18:1421-1429.

86. Duong T, Proulx S, Luciani P, et al. Genetic ablation of SOX18 function suppresses tumor lymphangiogenesis and metastasis of melanoma in Mice. Cancer Res. 2012;72:3105-3114.

87. Yoshimatsu Y, Yamazaki T, Mihira H, et al. Ets family members induce lymphangiogenesis through physical and functional interaction with Prox1. J Cell Sci. 2011;124:2753-2762.

88. Matsuo T, Miyata Y, Mitsunari K, et al. Pathological significance and prognostic implications of heme oxygenase 1 expression in non-muscle-invasive bladder cancer: correlation with cell proliferation, angiogenesis, lymphangiogenesis and expression of VEGFs and COX-2. Oncol Lett. 2016;13(1):275.

89. Wicki A, Lehembre F, Wick N, et al. Tumor invasion in the absence of epithelial-mesenchymal transition: podoplanin-mediated remodeling of the actin cytoskeleton. Cancer Cell. 2006;9(4):261-272.

90. Schacht V, Dadras SS, Johnson LA, et al. Up-regulation of the lymphatic marker podoplanin, a mucin-type transmembrane glycoprotein, in human squamous cell carcinomas and germ cell tumors. Am J Pathol. 2005;166(3):913-921.

91. Ma Y, Hou Y, Liu B, et al. Intratumoral lymphatics and lymphatic vessel invasion detected by D2-40 are essential for lymph node metastasis in bladder transitional cell carcinoma. Anat Rec. 2010;293(11):1847-1854.

92. Miyata Y, Watanabe S, Sagara Y, et al. High expression of HuR in cytoplasm, but not nuclei, is associated with malignant aggressiveness and prognosis in bladder cancer. PLoS One. 2013;8(3):e59095.

93. Lotan Y. Editorial comment on: prognostic implications of lymphangiogenesis in muscle-invasive transitional cell carcinoma of the bladder. Eur Urol. 2008;53(3):579-580.
94. Hanahan D, Weinberg RA. Hallmarks of cancer: the next generation. Cell. 2011;144(5):646-674.

95. Stacker SA, Williams SP, Karnezis T, et al. Lymphangiogenesis and lymphatic vessel remodelling in cancer. Nat Rev Cancer. 2014;14 (3):159-172.

96. Jones D, Pereira ER, Padera TP. Growth and immune evasion of lymph node metastasis. Front Oncol. 2018;8:36.

97. Benoit T, Keller EX, Wolfsgruber P, et al. High VEGF-D and low MMP-2 serum levels predict nodal-positive disease in invasive bladder cancer. Med Sci Monit. 2015;21:2266-2274.

98. Poyet C, Thomas L, Benoit TM, et al. Implication of vascular endothelial growth factor $\mathrm{A}$ and $\mathrm{C}$ in revealing diagnostic lymphangiogenic markers in node-positive bladder cancer. Oncotarget. 2017;8(13):21871-21883.

99. Johns Scott C, Yin X, Jeltsch M, et al. Functional Importance of a proteoglycan coreceptor in pathologic lymphangiogenesis. Circ Res. 2016;119(2):210-221.

100. Rauniyar K, Jha SK, Jeltsch M. Biology of vascular endothelial growth factor $\mathrm{C}$ in the morphogenesis of lymphatic vessels. Front Bioeng Biotechnol. 2018;6:7. doi:10.3389/fbioe.2018.00007

101. Karpanen T, Heckman C, Keskitalo S, et al. Functional interaction of VEGF-C and VEGF-D with neuropilin receptors. Faseb J. 2006;20:1462-1472. doi:10.1096/fj.05-5646com

102. Harris N, Paavonen K, Davydova N, et al. Proteolytic processing of vascular endothelial growth factor-D is essential for its capacity to promote the growth and spread of cancer. Faseb J. 2011;25:26152625. doi:10.1096/fj.10-179788

103. Chung AS, Ferrara N. Developmental and pathological angiogenesis. Annu Rev Cell Dev Biol. 2010;27:563-584. doi:10.1146/ annurev-cellbio-092910-154002

104. Anisimov A, Alitalo A, Korpisalo P, et al. Activated forms of VEGF-C and VEGF-D provide improved vascular function in skeletal muscle. Circ Res. 2009;104(11):1302-1312. doi:10.1161/ CIRCRESAHA.109.197830

105. Bui HM, Enis D, Robciuc MR, et al. Proteolytic activation defines distinct lymphangiogenic mechanisms for VEGFC and VEGFD. J Clin Invest. 2016;126(6):2167-2180. doi:10.1172/ JCI83967

106. Roukens MG, Peterson-Maduro J, Padberg Y, et al. Functional dissection of the CCBE1 protein: a crucial requirement for the collagen repeat domain. Circ Res. 2015;116(10):1660-1669. doi:10.1161/CIRCRESAHA.116.304949

107. McColl BK, Baldwin ME, Roufail S, et al. Plasmin activates the lymphangiogenic growth factors VEGF-C and VEGF-D. $J$ Exp Med. 2003;198(6):863-868. doi:10.1084/jem.20030361

108. Jha SK, Rauniyar K, Chronowska E, et al. KLK3/PSA and cathepsin D activate VEGF-C and VEGF-D. eLife. 2019;8. doi:10.7554/ eLife. 44478

109. Suzuki K, Morita T, Tokue A. Vascular endothelial growth factor-C (VEGF-C) expression predicts lymph node metastasis of transitional cell carcinoma of the bladder. Int J Urol. 2010;12(2):152158. doi:10.1111/j.1442-2042.2005.01010.x

110. Saharinen P, Tammela T, Karkkainen MJ, Alitalo K. Lymphatic vasculature: development, molecular regulation and role in tumor metastasis and inflammation. Trends Immunol. 2004;25(7):387395. doi:10.1016/j.it.2004.05.003

111. Khadim MT, Ahmed SA, Khan FA, Ikram A, Shaikh SY. Evaluation of vascular endothelial growth factors A, C and D as indicators of lymphangiogenesis and angiogenesis in invasive and non-invasive urothelial carcinoma bladder. J Pak Med Assoc. 2015;65(8):851-856.

112. Su JL, Yen CJ, Chen PS, et al. The role of the VEGF-C/VEGFR-3 axis in cancer progression. Br J Cancer. 2007;96(4):541-545. doi:10.1038/sj.bjc. 6603487 
113. Zhang HH, Qi F, Shi YR, et al. RNA interference-mediated vascular endothelial growth factor-C reduction suppresses malignant progression and enhances mitomycin $\mathrm{C}$ sensitivity of bladder cancer T24 cells. Cancer Biother Radiopharm. 2012;10(2):165.

114. Oka N, Yamamoto Y, Takahashi M, et al. Expression of angiopoietin-1 and -2 , and its clinical significance in human bladder cancer BJU Int. 2005;95(4):660. doi:10.1111/j.1464-410X.2005.05358.x

115. Fagiani E, Lorentz P, Kopfstein L, et al. Angiopoietin-1 and -2 exert antagonistic functions in tumor angiogenesis, yet both induce lymphangiogenesis. Cancer Res. 2011;71(17):5717-5727. doi:10.1158/0008-5472.CAN-10-4635

116. Zheng W, Nurmi H, Appak S, et al. Angiopoietin 2 regulates the transformation and integrity of lymphatic endothelial cell junctions. Genes Dev. 2014;28(14):1592-1603. doi:10.1101/gad.237677.114

117. Shojaei F, Lee JH, Simmons BH, et al. HGF/c-Met acts as an alternative angiogenic pathway in sunitinib-resistant tumors. Cancer Res. 2010;70(24):10090-10100. doi:10.1158/0008-5472. CAN-10-0489

118. Hass R, Jennek S, Yang Y, Friedrich K. c-Met expression and activity in urogenital cancers - novel aspects of signal transduction and medical implications. Cell Commun Signaling. 2017;15(1):10. doi:10.1186/s12964-017-0165-2

119. Cao R, Björndahl MA, Gallego MI, et al. Hepatocyte growth factor is a lymphangiogenic factor with an indirect mechanism of action. Blood. 2006;107(9):3531. doi:10.1182/blood-2005-06-2538

120. Shibue T, Weinberg RA. EMT, CSCs, and drug resistance: the mechanistic link and clinical implications. Nat Rev Clin Oncol. 2017;14(10):611. doi:10.1038/nrclinonc.2017.44

121. Yoo YA, Kang MH, Lee HJ, et al. Sonic hedgehog pathway promotes metastasis and lymphangiogenesis via activation of Akt, EMT, and MMP-9 pathway in gastric cancer. Cancer Res. 2011;71 (22):7061-7070. doi:10.1158/0008-5472.CAN-11-1338

122. Islam SS, Mokhtari RB, Noman AS, et al. Sonic hedgehog (Shh) signaling promotes tumorigenicity and stemness via activation of epithelial-to-mesenchymal transition (EMT) in bladder cancer. Mol Carcinog. 2016;55(5):537-551. doi:10.1002/mc.22300

123. Syed IS, Pedram A, Farhat WA. Role of Sonic Hedgehog (Shh) signaling in bladder cancer stemness and tumorigenesis. Curr Urol Rep. 2016;17(2):11. doi:10.1007/s11934-015-0568-9

124. Shin K, Lim A, Zhao C, et al. Hedgehog signaling restrains bladder cancer progression by eliciting stromal production of urothelial differentiation factors. Cancer Cell. 2014;26(4):521-533. doi:10.1016/j. ccell.2014.09.001

125. Shin K, Lim A, Odegaard JI, et al. Cellular origin of bladder neoplasia and tissue dynamics of its progression to invasive carcinoma. Nat Cell Biol. 2014;16(5):469-478. doi:10.1038/ncb2956

126. Shin K, Lee J, Guo N, et al. Hedgehog/Wnt feedback supports regenerative proliferation of epithelial stem cells in bladder. Nature. 2011;472(7341):110-114. doi:10.1038/nature09851

127. Islam SS, Mokhtari RB, Noman AS, et al. Sonic hedgehog (Shh) signaling promotes tumorigenicity and stemness via activation of epithelial-to-mesenchymal transition (EMT) in bladder cancer. $\mathrm{Mol}$ Carcinog. 2016;55(5):537-551. doi:10.1002/mc.22300

128. Takebe N, Harris PJ, Warren RQ, Ivy SP. Targeting cancer stem cells by inhibiting Wnt, notch, and hedgehog pathways. Nat Rev Clin Oncol. 2011;8(2):97-106. doi:10.1038/nrclinonc.2010.196

129. Cohen M, Kicheva A, Ribeiro A, et al. Ptch1 and Gli regulate Shh signalling dynamics via multiple mechanisms. Nat Commun. 2015;6:6709. doi:10.1038/ncomms7709

130. Li C, Du Y, Yang Z, et al. GALNT1-mediated glycosylation and activation of sonic hedgehog signaling maintains the self-renewal and tumor-initiating capacity of bladder cancer stem cells. Cancer Res. 2016;76(5):1273-1283. doi:10.1158/0008-5472.CAN-15-2309

131. Wang D, Kong X, Li Y, et al. Curcumin inhibits bladder cancer stem cells by suppressing sonic hedgehog pathway. Biochem Biophys Res Commun. 2017;493(1):521-527. doi:10.1016/j.bbrc.2017.08.158
132. He HC, Chen JH, Chen XB, et al. Expression of hedgehog pathway components is associated with bladder cancer progression and clinical outcome. Pathol Oncol Res. 2012;18(2):349-355. doi:10.1007/ s12253-011-9451-2

133. Aebischer D, Iolyeva M, Halin C. The inflammatory response of lymphatic endothelium. Angiogenesis. 2014;17(2):383-393. doi:10.1007/s10456-013-9404-3

134. Miteva DO, Rutkowski JM, Dixon JB, et al. Transmural flow modulates cell and fluid transport functions of lymphatic endothelium. Circ Res. 2010;106(5):920-931. doi:10.1161/CIRCRESAHA.109.207274

135. Muller A, Homey $\mathrm{B}$, Soto $\mathrm{H}$, et al. Involvement of chemokine receptors in breast cancer metastasis. Nature. 2001;410(6824):5056. doi: $10.1038 / 35065016$

136. Xiong Y, Huang F, Li X, et al. CCL21/CCR7 interaction promotes cellular migration and invasion via modulation of the MEK/ERK1/ 2 signaling pathway and correlates with lymphatic metastatic spread and poor prognosis in urinary bladder cancer. Int J Oncol. 2017;51(1):75-90. doi:10.3892/ijo.2017.4003

137. Fankhauser M, Broggi MAS, Potin L, et al. Tumor lymphangiogenesis promotes $\mathrm{T}$ cell infiltration and potentiates immunotherapy in melanoma. Sci Transl Med. 2017;9(407). doi:10.1126/scitranslmed. aal4712

138. Zhou J, Xiang Y, Yoshimura T, et al. The role of chemoattractant receptors in shaping the tumor microenvironment. Biomed Res Int. 2014;2014:751392. doi:10.1155/2014/751392

139. Pang MF, Georgoudaki AM, Lambut L, et al. TGF-beta1-induced EMT promotes targeted migration of breast cancer cells through the lymphatic system by the activation of CCR7/CCL21-mediated chemotaxis. Oncogene. 2016;35(6):748-760. doi:10.1038/onc.2015.133

140. Shields JD, Kourtis IC, Tomei AA, et al. Induction of lymphoidlike stroma and immune escape by tumors that express the chemokine CCL21. Science. 2010;328(5979):749-752. doi:10.1126/ science. 1185837

141. Evans JR, Feng FY, Chinnaiyan AM. The bright side of dark matter: IncRNAs in cancer. J Clin Invest. 2016;126(8):27752782. doi:10.1172/JCI84421

142. He W, Cai Q, Sun F, et al. linc-UBC1 physically associates with polycomb repressive complex 2 (PRC2) and acts as a negative prognostic factor for lymph node metastasis and survival in bladder cancer. Biochim Biophys Acta. 2013;1832(10):1528-1537. doi:10.1016/j.bbadis.2013.05.010

143. Prensner JR, Iyer MK, Sahu A, et al. The long noncoding RNA SChLAP1 promotes aggressive prostate cancer and antagonizes the SWI/SNF complex. Nat Genet. 2013;45(11):1392-1398. doi:10.1038/ ng. 2771

144. Gupta RA, Shah N, Wang KC, et al. Long non-coding RNA HOTAIR reprograms chromatin state to promote cancer metastasis. Nature. 2010;464(7291):1071-1076. doi:10.1038/ nature 08975

145. Hao Y, Yang X, Zhang D, et al. Long noncoding RNA LINC01186, regulated by TGF-beta/SMAD3, inhibits migration and invasion through epithelial-mesenchymal-transition in lung cancer. Gene. 2017;608:1-12. doi:10.1016/j.gene.2017.01.023

146. Yuan JH, Yang F, Wang F, et al. A long noncoding RNA activated by TGF-beta promotes the invasion-metastasis cascade in hepatocellular carcinoma. Cancer Cell. 2014;25(5):666-681. doi:10.1016/ j.ccr.2014.03.010

147. He $\mathrm{W}$, Zhong $\mathrm{G}$, Jiang $\mathrm{N}$, et al. Long noncoding RNA BLACAT2 promotes bladder cancer-associated lymphangiogenesis and lymphatic metastasis. J Clin Invest. 2018;128(2). doi:10.1172/JCI96218

148. Calin GA, Sevignani C, Dumitru CD, et al. Human microRNA genes are frequently located at fragile sites and genomic regions involved in cancers. Proc Natl Acad Sci U S A. 2004;101(9):29993004. doi:10.1073/pnas.0307323101 
149. Zhou XU, Qi L, Tong S, et al. miR-128 downregulation promotes growth and metastasis of bladder cancer cells and involves VEGFC upregulation. Oncol Lett. 2015;10(5):3183-3190. doi:10.3892/ ol.2015.3689

150. Bracher A, Soler Cardona A, Tauber S, et al. Epidermal growth factor facilitates melanoma lymph node metastasis by influencing tumor lymphangiogenesis. J Invest Dermatol. 2012;133:230-238.

151. Cao R, Björndahl MA, Religa P, et al. Erratum: PDGF-BB induces intratumoral lymphangiogenesis and promotes lymphatic metastasis (cancer cell (october 2004) 6 (333-345)). Cancer cell. 2004;6:333-345.

152. Cao R, Ji H, Feng N, et al. Collaborative interplay between FGF-2 and VEGF-C promotes lymphangiogenesis and metastasis. Proc Natl Acad Sci US A. 2012;109(39):15894-15899. doi:10.1073/pnas.1208324109

153. Björndahl M, Cao R, Johan Nissen L. Et Al: Insulin-Like Growth Factors 1 and 2 Induce Lymphangiogenesis in Vivo. Proc Natl Acad Sci. 2005;102:15593-15598.

154. Cattaneo F, Motterle G, Zattoni F, et al. The Role of Lymph Node Dissection in the Treatment of Bladder Cancer. Front Surg. 2018;5:62.

155. Wissmann C, Detmar M. Pathways targeting tumor lymphangiogenesis. Clin Cancer Res. 2006;12(23):6865-6868. doi:10.1158/1078-0432. CCR-06-1800

156. Achen MG, Mann GB, Stacker SA. Targeting lymphangiogenesis to prevent tumour metastasis. Br J Cancer. 2006;94(10):13551360. doi:10.1038/sj.bjc.6603120

157. Burton JB, Priceman SJ, Sung JL, et al. Suppression of prostate cancer nodal and systemic metastasis by blockade of the lymphangiogenic axis. Cancer Res. 2008;68(19):7828-7837. doi:10.1158/ 0008-5472.CAN-08-1488

158. Falchook GS, Goldman JW, Desai J, et al. A first-in-human phase I study of VGX-100, a selective anti-VEGF-C antibody, alone and in combination with bevacizumab in patients with advanced solid tumors. J Clin Oncol. 2014. doi:10.1200/jco.2014.32.15_suppl. 2524

159. Saif MW, Knost JA, Chiorean EG, et al. Phase 1 study of the anti-vascular endothelial growth factor receptor 3 monoclonal antibody LY3022856/IMC-3C5 in patients with advanced and refractory solid tumors and advanced colorectal cancer. Cancer Chemother Pharmacol. 2016;78(4):815-824. doi:10.1007/s002 80-016-3134-3

160. Nokihara H, Yamamoto N, Yamada Y, et al. A phase 1 study of ramucirumab in Japanese patients with advanced solid tumors. Jpn J Clin Oncol. 2017;47(4):298-305. doi:10.1093/jjco/hyx008

161. Achen MG, Roufail S, Domagala T, et al. Monoclonal antibodies to vascular endothelial growth factor-D block its interactions with both VEGF receptor-2 and VEGF receptor-3. Eur J Biochem. 2000;267:2505-2515. doi:10.1046/j.1432-1327.2000.01257.x

162. Davydova N, Roufail S, Streltsov V, et al. The VD1 neutralizing antibody to vascular endothelial growth factor-D: binding epitope and relationship to receptor binding. J Mol Biol. 2011;407:581593. doi:10.1016/j.jmb.2011.02.009

163. Kashima K, Watanabe M, Satoh Y, et al. Abstract LB-327: inhibition of lymphatic metastasis in neuroblastoma by a novel neutralizing antibody to vascular endothelial growth factor-D. Cancer Sci. 2012;103(12):2144-2152.

164. Albuquerque RJC, Hayashi T, Cho WG, et al. Alternatively spliced vascular endothelial growth factor receptor-2 is an essential endogenous inhibitor of lymphatic vessel growth. Nat Med. 2009; 15:1023. doi:10.1038/nm.2018

165. Gherardi E, Birchmeier W, Birchmeier C, et al. Targeting MET in cancer: rationale and progress. Nat Rev Cancer. 2012;12(2):89103. doi: $10.1038 / \mathrm{nrc} 3205$

166. Hong DS, Rosen P, Lockhart AC, et al. A first-in-human study of AMG 208, an oral MET inhibitor, in adult patients with advanced solid tumors. Oncotarget. 2015;6(21):18693-18706. doi:10.18632/oncotarget.4472
167. Diamond JR, Salgia R, Varella-Garcia M, et al. Initial clinical sensitivity and acquired resistance to MET inhibition in METmutated papillary renal cell carcinoma. J Clin Oncol. 2013;31 (16):e254-e258. doi:10.1200/JCO.2012.46.4289

168. Choueiri TK, Vaishampayan U, Rosenberg JE, et al. Phase II and biomarker study of the dual MET/VEGFR2 inhibitor foretinib in patients with papillary renal cell carcinoma. J Clin Oncol. 2013;31 (2):181-186. doi:10.1200/JCO.2012.43.3383

169. Eklund L, Saharinen P. Angiopoietin signaling in the vasculature. Exp Cell Res. 2013;319(9):1271-1280.

170. Cortes J, Talpaz M, Smith HP, et al. Phase 1 dose-finding study of rebastinib (DCC-2036) in patients with relapsed chronic myeloid leukemia and acute myeloid leukemia. Haematologica. 2017;102(3):519528.

171. O'Hare T, Zabriskie MS, Eiring AM, et al. Pushing the limits of targeted therapy in chronic myeloid leukaemia. Nat Rev Cancer. 2012;12(8):513-526.

172. Kane RC, Farrell AT, Saber H, et al. Sorafenib for the treatment of advanced renal cell carcinoma. Clin Cancer Res. 2006;12 (24):7271-7278.

173. Verweij J, Sleijfer S. Pazopanib, a new therapy for metastatic soft tissue sarcoma. Expert Opin Pharmacother. 2013;14(7):929-35.

174. Mankal P, O'Reilly E. Sunitinib malate for the treatment of pancreas malignancies - where does it fit? Expert Opin pharmacother. 2013;14.

175. Kodera Y, Katanasaka Y, Kitamura Y, et al. Sunitinib inhibits lymphatic endothelial cell functions and lymph node metastasis in a breast cancer model through inhibition of vascular endothelial growth factor receptor 3. Breast Cancer Res. 2011;13(3):R66.

176. Grünwald V, Merseburger A. Axitinib for the treatment of patients with advanced metastatic renal cell carcinoma (mRCC) after failure of prior systemic treatment. Onco Targets Ther. 2012;5:111-117.

177. Davis SL, Eckhardt S, Messersmith WA, et al. The development of regorafenib and its current and potential future role in cancer therapy. Drugs Today (Barc). 2013;49:105-115.

178. Los M, Roodhart JM, Voest EE. Target practice: lessons from phase III trials with bevacizumab and vatalanib in the treatment of advanced colorectal cancer. Oncologist. 2007;12(4):443-450.

179. Caunt M, Mak J, Liang WC, et al. Blocking neuropilin-2 function inhibits tumor cell metastasis. Cancer Cell. 2008;13(4):331-342.

180. Karnezis T, Shayan R, Caesar C, et al. VEGF-D promotes tumor metastasis by regulating prostaglandins produced by the collecting lymphatic endothelium. Cancer Cell. 2012;21:181-195.

181. Karnezis T, Shayan R, Fox S, et al. The connection between lymphangiogenic signalling and prostaglandin biology: A missing link in the metastatic pathway. Oncotarget. 2012;3:890-903.

182. Mumprecht V, Honer M, Vigl B, et al. In vivo imaging of inflammation- and tumor-induced lymph node lymphangiogenesis by immuno-positron emission tomography. Cancer Res. 2010;70 (21):8842-8851.

183. Siefker-Radtke A, Curti B. Immunotherapy in metastatic urothelial carcinoma: focus on immune checkpoint inhibition. Nat Rev Urol. 2018;15(2):112-124.

184. Redelman-Sidi G, Glickman M, Bochner B. The mechanism of action of BCG therapy for bladder cancer-A current perspective. Nat Rev Urol. 2014 Mar;11(3):153-162.

185. Lund A, Wagner M, Fankhauser M, et al. Lymphatic vessels regulate immune microenvironments in human and murine melanoma. Journal of clinical investigation. 2016;126:3389-3402.

186. Kimura T, Sugaya M, Oka T, et al. Lymphatic dysfunction attenuates tumor immunity through impaired antigen presentation. Oncotarget. 2015;6:18081.

187. Maisel K, Sasso MS, Potin L, et al. Exploiting lymphatic vessels for immunomodulation: rationale, opportunities, and challenges. Advanced drug delivery reviews. 2017;114:43-59. 
188. Bora C, Prabhu R, Patravale V. Lymphatic delivery: concept, challenges and applications (INDIAN DRUGS best review article award 2017). Indian Drugs. 2017;54:5-22.

189. Chaudhary S, Garg T, Rayasa M, et al. Recent approaches of lipidbased delivery system for lymphatic targeting via oral route. J Drug Target. 2014;22(10):871-882.

190. Nörder M, Gutierrez M, Zicari S, et al. Lymph node-derived lymphatic endothelial cells express functional costimulatory molecules and impair dendritic cell-induced allogenic T-cell proliferation. FASEB J. 2012;26:2835-2846.
191. Lukacs-Kornek V, Malhotra D, Fletcher AL, et al. Regulated release of nitric oxide by nonhematopoietic stroma controls expansion of the activated $\mathrm{T}$ cell pool in lymph nodes. Nat Immunol. 2011;12:1096.

192. Garnier L, Gkountidi A-O, Hugues S. Tumor-associated lymphatic vessel features and immunomodulatory functions. Front Immunol. 2019;10(720):720.

193. Dieterich L, Detmar M. Tumor lymphangiogenesis and new drug development. Adv Drug Delivery Rev. 2015;99:148-160.

\section{Publish your work in this journal}

OncoTargets and Therapy is an international, peer-reviewed, open access journal focusing on the pathological basis of all cancers, potential targets for therapy and treatment protocols employed to improve the management of cancer patients. The journal also focuses on the impact of management programs and new therapeutic

Submit your manuscript here: https://www.dovepress.com/oncotargets-and-therapy-journal agents and protocols on patient perspectives such as quality of life, adherence and satisfaction. The manuscript management system is completely online and includes a very quick and fair peer-review system, which is all easy to use. Visit http://www.dovepress.com/ testimonials.php to read real quotes from published authors. 